\title{
PEMETAAN SEKOLAH DI TANAH DATAR (Sebuah Kajian dan Rekomendasi)
}

\author{
Oleh: Sirajul Munir*
}

\begin{abstract}
Data provider as the main input in planning and formulating policies is a very important thing in education field. Consequently, school mapping, a micro or regional educational planning approach to figure out the efficiency and effectiveness of education process, is urgently needed. From school mapping conducted in Tanah Datar, it was found that: (1) significant overloaded of elementary (SD) and junior high school (SMP) teachers, (2) the educational qualification of many teachers in those levels are still bachelor (diploma) bolders, (3) teachers are not well distributed.
\end{abstract}

Kata Kunci: pemetaan sekolah, regrouping, multi-grade, kelebihan guru, dan kualifikasi

\section{PENDAHULUAN}

$\mathrm{P}$ endidikan merupakan salah satu faktor penentu keberhasilan seseorang dalam mencapai tujuan hidupnya. Oleh karena itu pemerintah selalu berupaya dalam meningkatkan pelayanan pendidikan dengan menyediakan sekolah mulai dari jenjang pendidikan dasar sampai ke jenjang pendidikan tinggi.

Pendidikan juga dapat membuka wawasan, meningkatkan pengetahuan dan keterampilan seseorang dalam melaksanakan tugas dan kewajiban yang diembannya. Dengan demikian dapat disimpulkan bahwa semakin tinggi tingkat pendidikan seseorang akan berdampak pada peningkatan kualitas dan kemampuan seseorang dalam melaksanakan tugasnya.

Di dunia pendidikan masih banyak ditemukan tenaga pendidik dan tenaga kependidikan yang berpendidikan relatif belum memenuhi standar minimal sebagaimana yang dituntut oleh UU No 14 tahun 2005 tentang guru dan dosen bahwa mereka harus memiliki pendidikan minimal S1 atau D4.

Berdasarkan data guru SD yang diperoleh di Kecamatan Padang Ganting, misalnya, telihat bahwa persentase guru yang berkualifikasi S1 baru berkisar 10 persen sementara 90 lainnya masih berpendidikan D3, D2 bahkan SLTA. Kondisi ini juga terjadi beberapa kecamatan seperti Tanjung Emas, Sungayang dan Batipuh. Hal ini berdampak terhadap proses pembelajaran seperti strategi guru yang kurang variatif, manajemen kelas yang kurang efektif, dan materi pembelajaran yang out-fashion.

Menyahuti kondisi ini pemerintah secara proaktif melahirkan berbagai kebijakan yang tidak lain bertujuan untuk meningkatkan mutu pendidik. Antara lain UU No 14 tahun 2005 tentang UU Guru dan Dosen, Surat Edaran Mendiknas tanggal 21 Mei Nomor 54/MPN/KP/2006 perihal Pendidikan Profesi dan

* Penulis adalah Lektor dalam Mata Kuliah Bahasa Inggris pada STAIN Batusangkar 
Sertifikasi, dan Peraturan Pemerintah tentang Standar Nasional Pendidikan.

Dalam tahap perencanaan dan perumusan kebijakan, pemerintah dalam hal ini membutuhkan data-data yang valid dan akurat agar permasalahan yang ada dapat diselesaikan dengan efektif dan efisien. Untuk itu pengadaan data menjadi sesuatu yang sangat vital. Ketidakakuratan data akan berdampak terhadap pengambilan kebijakan.

Seiring dengan ini, Pemerintah Daerah Kabupaten Tanah Datar di bawah Dinas Pendidikan Tenaga Kerja mengadakan Workshop School Mapping (Pemetaan Sekolah) dan Madrasah tingkat Pendidikan Dasar yang melibatkan seluruh kepala cabang dinas 14 kecamatan di Tanah Datar dan Mapenda Departemen Agama Tanah Datar. Dari workshop tersebut diperoleh data yang akurat yang menggambarkan pemetaan pendidikan di masing-masing kecamatan baik menyangkut rasio guru dan siswa, kualifikasi pendidik, distribusi pendidik, dan lain sebagainya.

Berdasarkan data yang diperoleh dari workshop tersebut ditemukan berbagai masalah yang membutuhkan perhatian serius untuk ditindaklanjuti oleh berbagai pihak seperti Dinas Pendidikan Tenaga Kerja, Mapenda Depag Tanah Datar, dan stake holder lainnya yang berkecimpung di dunia pendidikan. Adapun permasalahan yang ditemukan antara lain banyaknya guru yang belum berkualifikasi S1, distribusi guru yang belum merata, dan disefisiensi tenaga pendidik dan tenaga kependidikan disamping hal-hal lain yang layak untuk didiskusikan.

Tulisan ini pada dasarnya ingin menggambarkan pemetaan data sekolah dan tenaga pendidik perkecamatan diiringi dengan beberapa rekomendasi.

\section{KAJIAN TEORI}

\section{Pemetaan Sekolah}

Pemetaan sekolah merupakan suatu pendekatan perencanaan pendidikan micro atau regional dengan tujuan penyediaan alat-alat dan fasilitas pendidikan untuk menutup SD yang tidak efisien dengan menetapkan daerah jangkauan sesuai dengan perkembangan wilayah mulai dari tingkat kecamatan, kabupaten/ kota hingga propinsi agar dapat diperoleh gambaran yang akurat tentang kondisi ril pendidikan dasar yang telah ditetapkan.

Managing Basic Education (2008) lebih jauh mengatakan bahwa tujuan pemetaan pendidikan adalah agar daerah mampu melakukan analisis kebutuhan program peningkatan pendidikan untuk mendukung proses perencanaan program pendidikan berdasarkan data pemetaan.

Pemetaan sekolah setidaknya harus mencakup 3 aspek: sekolah, guru, dan siswa. Untuk sekolah harus dipetakan jumlah sekolah, jarak antar sekolah, dan sarana prasarana. Sementara itu, untuk guru pemetaan selayaknya mencakup jumlah guru, rasio guru dan siswa, status guru, kebutuhan guru, dan kualifikasi pendidikan guru. Terakhir, untuk siswa harus mencakup jumlah siswa, jumlah rombongan belajar setiap kelas, penduduk usia sekolah (7 tahun - 15 tahun).

\section{Multi Grade Teaching}

Departemen Pendidikan Nasional (2005) menjelaskan Multi-grade (pembelajaran kelas rangkap) adalah kelas yang yang terdiri dari siswa siswi dari beberapa (2 dan 3) tingkat kelas dengan seorang guru untuk satu tahun ajaran.

Multi grade digunakan untuk menggambarkan pengajaran di sekolah dasar dengan cara menggabungkan dua kelas yang berbeda menjadi satu kelas. Birch dan Mike Lally (2005) mengemukakan bahwa istilah multi grade teaching diaplikasikan secara bervariasi 
oleh berbagai negera. Di Nepal, misalnya, multi grade teaching adalah sebuah pola pengajaran di mana guru mengajar lebih dari satu kelas pada satu kelas yang sama atau pada kelas yang berbeda. Sementara itu, di Malaysia pola multi grade melibatkan pengajaran siswa yang menggabungkan dua kelas atau lebih dalam satu kelas yang sama. Penggabungan kelas tersebut mengacu ke kelas yang lebih dekat. Misalnya kelas I digabung dengan kelas II, kelas III dengan kelas IV, dan kelas V dengan kelas VI

Di China, kelas multi grade teaching lebih rumit. Dimana dua kelas yang berbeda umur dan kemampuan digabung menjadi satu. Bahkan China Selatan dan China Barat yang memiliki bahasa Ibu yang berbeda digabung menjadi satu. Tugas guru juga lebih rumit, bagaimana cara mengajar anak yang memiliki latar belakang bahasa yang berbeda pada satu kelas yang sama dan pada waktu yang sama.

Di Indonesia, multi grade teaching adalah pola dimana guru menggabungkan dua kelas yang siswanya berjumlah sedikit pada waktu yang sama baik pada kelas yang berbeda maupun pada kelas yang dipisah melalui sekat.

\section{Regrouping}

Regrouping adalah penggabungan beberapa sekolah (biasanya dua sekolah menjadi satu (Managing Basic Education: 2008). Biasanya dua sekolah yang berdekatan tersebut memiliki jarak kurang dari 1000 meter. Sekolah yang digabung akan berdampak terhadap efisiensi tenaga pendidik dan tenaga kependidikan.

Jika sekolah yang jumlah muridnya sedikit, tetapi lokasinya berjauhan (sehingga menyulitkan regrouping) yang dilakukan adalah mengubah status dari SD konvensional (dengan 6 guru kelas) menjadi SD kecil (dengan 3 guru kelas). Sementara itu untuk sekolah-sekolah swasta, keputusan diserahkan kepada pengelola sekolah, tetapi Pemda menentukan syarat jumlah murid minimal untuk dapat menerima bantuan tertentu.

\section{Kualifikasi}

Kualifikasi pendidikan untuk guru SD dan SMP secara jelas disebutkan pada UU No 14 tahun 2005 tentang Guru dan Dosen bahwa mereka minimal harus berpendidikan S1 atau D4. Secara detil bisa dilihat pada Bab IV pasal 8 berikut ini: "guru wajib memiliki kualifikasi akademik, kompetensi, sertifikasi pendidik, sehat jasmani dan rohani, serta memiliki kemampuan untuk mewujudkan tujuan pendidikan nasional". Dan Pasal 9 disebutkan pula "Kualifikasi akademik sebagaimana dimaksud dalam pasal 8 diperoleh melalui pendidikan tinggi program sarjana atau program diploma empat." Dari sini terlihat bahwa seorang guru wajib memiliki kualifikasi pendidikan minimal S1 atau D4.

Lebih lanjut diterangkan oleh Surat Edaran Mentri Pendidikan Nasional tanggal 21 Mei Nomor : 54/MPN/KP/2006 perihal Pendidikan Profesi dan Sertifikasi antara lain dinyatakan bahwa:

Lembaga pendidikan profesi dan sertifikasi pendidikan adalah perguruan tinggi yang memilki program pengadaan tenaga kependidikan yang terakreditasi dan ditunjuk oleh pemerintah.

Bagi guru yang akan meningkatkan kualifikasinya diarahkan untuk mengambil program Diploma 4 atau Strata 1 dari perguruan tinggi terakreditasi dan program studi yang sesuai dengan mata pelajaran yang diasuh guru. Bagi guru SD diarahkan untuk mengambil kualifikasi S1 Pendidikan guru Sekolah Dasar untuk Guru TK, S1 PGTK/ Psikologi

Pemerintah hanya mengakui sertifikasi yang dikeluarkan oleh perguruan tinggi yang memiliki program pengadaan tenaga kependidikan yang terakreditasi dan ditunjuk oleh pemerintah. 
Berdasarkan pernyataan di atas dapat disimpulkan bahwa: Guru SD atau SMP mesti memilki kualifikasi Strata 1 atau Diploma IV. Jika guru belum memiliki kualifikasi Strata 1 atau Diploma IV diharuskan melanjutkan pendidikan ke perguruan tinggi yang sudah terakrediatasi.Guru SD harus melanjutkan pendidikan ke PGSD Strata 1 sementara untuk guru SMP harus sesuai dengan mata pelajaran yang diampu. Perguruan Tinggi yang dipilih guru harus Perguruan Tinggi yang mencetak tenaga kependidikan yang terakreditasi oleh pemerintah.

\section{PEMBAHASAN}

\section{Data Sekolah, Guru, dan Siswa}

\section{Jumlah Sekolah}

Secara umum jumlah sekolah di Tanah Datar dapat dipaparkan sebagai berikut:

Tabel 1 Jumlah Sekolah

\begin{tabular}{|l|l|l|l|}
\hline NO & KECAMATAN & SD/MI & SMP/MTs \\
\hline 1 & X Koto & 34 & 10 \\
\hline 2 & Batipuh & 29 & 8 \\
\hline 3 & Batipuh Selatan & 12 & 8 \\
\hline 4 & Pariangan & 22 & 7 \\
\hline 5 & Rambatan & 31 & 10 \\
\hline 6 & Lima Kaum & 27 & 10 \\
\hline 7 & Tanjung Emas & 19 & 4 \\
\hline 8 & Padang Ganting & 13 & 3 \\
\hline 9 & Lintau Buo & 13 & 5 \\
\hline 10 & $\begin{array}{l}\text { Lintau Buo } \\
\text { Utara }\end{array}$ & 35 & 9 \\
\hline 11 & Sungayang & 14 & 6 \\
\hline 12 & Sungai Tarab & 27 & 6 \\
\hline 13 & Salimpaung & 19 & 6 \\
\hline 14 & Tanjung Baru & 19 & 3 \\
\hline
\end{tabular}

(Sumber: Workshop Analisis Data Kabupaten Tanah Datar, November 2008)

Data di atas menggambarkan bahwa jumlah sekolah sangat bervariasi sesuai dengan kepadatan penduduk masing-masing kecamatan. Pada kecamat- an X Koto, misalnya, terlihat jumlah sekolah lebih banyak mengingat jumlah populasi penduduk juga padat. Sementara itu pada Kecamatan Batipuh Selatan jumlah sekolah lebih sedikit karena hitungan populasi jumlah penduduk juga sedikit.

\section{Jumlah Guru dan Siswa}

Table 2 Jumlah Guru dan Siswa

\begin{tabular}{|c|c|c|c|c|c|}
\hline No & $\begin{array}{l}\text { Kecama } \\
\text { tan }\end{array}$ & $\begin{array}{l}\text { Guru } \\
\mathrm{SD} / \\
\mathrm{MI}\end{array}$ & $\begin{array}{l}\text { Sis } \\
\text { wa } \\
\text { SD/ } \\
\text { MI }\end{array}$ & $\begin{array}{l}\text { Guru } \\
\text { smp/ } \\
\text { MTS }\end{array}$ & $\begin{array}{l}\text { Sis } \\
\text { wa } \\
\text { smp } \\
\text { / } \\
\text { mts }\end{array}$ \\
\hline 1 & X Koto & 344 & 5054 & 138 & $\begin{array}{l}210 \\
7\end{array}$ \\
\hline 2 & Batipuh & 268 & 4168 & 126 & $\begin{array}{l}140 \\
0\end{array}$ \\
\hline 3 & $\begin{array}{l}\text { Batipuh } \\
\text { Selatan }\end{array}$ & 108 & 1491 & 76 & 608 \\
\hline 4 & $\begin{array}{l}\text { Pariang } \\
\text { an }\end{array}$ & 133 & 2424 & 107 & 976 \\
\hline 5 & $\begin{array}{l}\text { Rambat } \\
\text { an }\end{array}$ & 230 & 4375 & 251 & $\begin{array}{l}167 \\
5\end{array}$ \\
\hline 6 & $\begin{array}{l}\text { Lima } \\
\text { Kaum }\end{array}$ & 179 & 4988 & 308 & $\begin{array}{l}575 \\
9\end{array}$ \\
\hline 7 & $\begin{array}{l}\text { Tanjung } \\
\text { Emas }\end{array}$ & 120 & 2383 & 94 & 937 \\
\hline 8 & $\begin{array}{l}\text { Padang } \\
\text { Ganting }\end{array}$ & 109 & 1887 & 67 & 669 \\
\hline 9 & $\begin{array}{l}\text { Lintau } \\
\text { Buo }\end{array}$ & 110 & 2375 & 113 & $\begin{array}{l}100 \\
2\end{array}$ \\
\hline 10 & $\begin{array}{l}\text { Lintau } \\
\text { Buo } \\
\text { Utara }\end{array}$ & 249 & 4748 & 80 & $\begin{array}{l}162 \\
7\end{array}$ \\
\hline 11 & $\begin{array}{l}\text { Sungay } \\
\text { ang }\end{array}$ & 154 & 2290 & 66 & 867 \\
\hline 12 & $\begin{array}{l}\text { Sungai } \\
\text { Tarab }\end{array}$ & 117 & 1665 & 103 & $\begin{array}{l}104 \\
9\end{array}$ \\
\hline 13 & $\begin{array}{l}\text { Salimpa } \\
\text { ung }\end{array}$ & 110 & 2703 & 65 & 838 \\
\hline 14 & $\begin{array}{l}\text { Tanjung } \\
\text { Baru }\end{array}$ & 164 & 1712 & 91 & 359 \\
\hline
\end{tabular}

(Sumber: Workshop Analisis Data Kabupaten Tanah Datar, November 2008) 
Jika diamati tabel di atas tergambar bahwa rasio antara guru dan siswa pada SD/ MI adalah 1:18, sementara itu rasio guru dan siswa pada SMP/ MTs adalah 1:12. Ini menunjukkan bah-wa secara rasio yang telah ditetapkan oleh PMPTK -- 1:28 untuk SD/MI dan 1:32 untuk SMP/ MTs), jumlah guru SD dan SMP sangat memadai bahkan berlebih. Sementara selama ini per-hitungan selalu dilakukan dalam bentuk rombongan belajar (rombel). Sebagai ilustrasi jika kelas satu terdiri dari 15 orang siswa yang diajar oleh oleh 1 orang guru dan kelas dua dengan jumlah siswa terdiri dari 10 orang yang diajar oleh satu guru maka perhitungan ter-sebut menggunakan pola perhitungan rombel. Meskipun hanya ada beberapa murid di kelas (kadang-kadang kurang dari 7 orang) tetap dianggap perlu ada satu guru kelas. Akibatnya ada beberapa guru memiliki sedikit murid (sering di bawah 15 orang), sedangkan guru lain harus meng-ajar lebih dari 50 orang.

Di sebagian besar negara guru dialokasikan ke sekolah berdasarkan jumlah murid bukan jumlah rombongan belajar. Misalnya di beberapa daerah di India, seperti diungkapkan oleh Managing Basic Education, guru dialokasikan ke sekolah satu guru dibanding $40 \mathrm{mu}-$ rid. Di Indonesia sendiri berdasarkan rambu-ramu yang ditetapkan oleh lembaga Penjaminan Mutu Pendidikan dan Tenaga Kependidikan (PMPTK) bahwa hitungan harus menurut hitungan antara guru dan siswa. Rasio tersebut adalah 1:28. Artinya 1 guru dan 28 siswa.

Dari alasan di atas dapat direkomendasikan bahwa PEMDA Tanah Datar tidak perlu mengadakan pengangkatan tenaga pendidik dan tenaga Kependidikan Tingkat SD/ MI dan SMP/MTs untuk tahun 2008 -2010. Bahkan pada beberapa Sekolah Dasar di $\mathrm{X}$ Koto, Batipuh, dan Batipuh Selatan sangat dirasakan terjadi penumpukan guru. Artinya jumlah guru tidak se- banding dengan jumlah siswa yang sangat sedikit. Hal ini dapat diamati pada tabel berikut ini:

Tabel 3 Data Sekolah yang Memiliki Jumlah Siswa yang Sedikit

\begin{tabular}{|c|c|c|c|}
\hline No & Kecamatan & $\begin{array}{l}\text { Sekolah Multi- } \\
\text { Grade }\end{array}$ & $\begin{array}{l}\text { Jumlah } \\
\text { Siswa }\end{array}$ \\
\hline 1 & X Koto & $\begin{array}{l}\text { 1. SDN } 13 \\
\text { Hilir Balai }\end{array}$ & 75 \\
\hline \multirow[t]{4}{*}{2} & Batipuh & $\begin{array}{l}\text { 1. SDN } 12 \\
\text { Batipuh }\end{array}$ & 58 \\
\hline & & $\begin{array}{l}\text { 2. SDN } 26 \\
\text { Batipuh }\end{array}$ & 62 \\
\hline & & $\begin{array}{l}\text { 3. SDN } 34 \\
\text { Batipuh }\end{array}$ & 75 \\
\hline & & 4. MIS Pitalah & 36 \\
\hline \multirow[t]{4}{*}{3} & $\begin{array}{l}\text { Batipuh } \\
\text { Selatan }\end{array}$ & $\begin{array}{l}\text { 1. SDN } 39 \\
\text { Batipuh }\end{array}$ & 87 \\
\hline & & $\begin{array}{l}\text { 2. SDN } 07 \\
\text { Batipuh }\end{array}$ & 88 \\
\hline & & $\begin{array}{l}\text { 3. SDN } 44 \\
\text { Batipuh }\end{array}$ & 90 \\
\hline & & $\begin{array}{l}\text { 4. SDN } 49 \\
\text { Batipuh }\end{array}$ & 73 \\
\hline \multirow[t]{7}{*}{4} & Pariangan & $\begin{array}{l}\text { 1. SDN } 09 \\
\text { Labuatan }\end{array}$ & 47 \\
\hline & & $\begin{array}{l}\text { 2. SDN } 14 \\
\text { Batur }\end{array}$ & 58 \\
\hline & & $\begin{array}{l}\text { 3. SDN } 16 \\
\text { Bulan Sarik }\end{array}$ & 58 \\
\hline & & $\begin{array}{lr}\text { 4. SDN } 22 \\
\text { Pariangan }\end{array}$ & 70 \\
\hline & & $\begin{array}{l}\text { 5. SDN } 25 \\
\text { Simabur }\end{array}$ & 56 \\
\hline & & $\begin{array}{l}\text { 6. SDN } 27 \\
\text { Sialahan }\end{array}$ & 48 \\
\hline & & $\begin{array}{l}\text { 7.SDN } 28 \\
\text { Buluh Kasok }\end{array}$ & 64 \\
\hline \multirow[t]{3}{*}{5} & Rambatan & $\begin{array}{l}\text { 1. SDN } 14 \text { III } \\
\text { Koto }\end{array}$ & 81 \\
\hline & & $\begin{array}{l}\text { 2. SDN } 35 \\
\text { Pialai } \\
\text { Balimbing }\end{array}$ & 33 \\
\hline & & $\begin{array}{l}\text { 3. SDN } 36 \\
\text { Batu Limbak }\end{array}$ & 58 \\
\hline \multirow[t]{3}{*}{6} & $\begin{array}{l}\text { Tanjung } \\
\text { Emas }\end{array}$ & $\begin{array}{ll}\text { 1. SDN } 09 \\
\text { Talago } \\
\text { Gunung }\end{array}$ & 77 \\
\hline & & $\begin{array}{l}\text { 2. SDN } 29 \\
\text { Padang Datar }\end{array}$ & 89 \\
\hline & & $\begin{array}{l}\text { 3.SDN } 35 \\
\text { Saruaso Utara }\end{array}$ & 66 \\
\hline 7 & Lintau Buo & 1. SDN 45 & 46 \\
\hline
\end{tabular}




\begin{tabular}{|c|c|c|c|}
\hline & Utara & Pamasihan & \\
\hline & & $\begin{array}{l}\text { 2. SDN } 14 \\
\text { Tuanku Amir }\end{array}$ & 77 \\
\hline & & $\begin{array}{l}\text { 3. SDN } 50 \\
\text { Pasa Laweh }\end{array}$ & 87 \\
\hline 8 & Sungayang & $\begin{array}{l}\text { 1. SDN } 22 \\
\text { Sungayang }\end{array}$ & 44 \\
\hline \multirow[t]{4}{*}{9} & $\begin{array}{l}\text { Sungai } \\
\text { Tarab }\end{array}$ & $\begin{array}{l}\text { 1. SDN } 05 \\
\text { Sungai Tarab }\end{array}$ & 80 \\
\hline & & $\begin{array}{l}\text { 2. SD } 16 \\
\text { Sungai Tarab }\end{array}$ & 84 \\
\hline & & $\begin{array}{l}\text { 3. SDN } 19 \\
\text { Sungai Tarab }\end{array}$ & 81 \\
\hline & & $\begin{array}{l}\text { 4. SDN } 25 \\
\text { Sungai Tarab }\end{array}$ & 77 \\
\hline \multirow[t]{2}{*}{10} & Salimpaung & $\begin{array}{l}\text { 1. SDN } 10 \\
\text { Sumanik }\end{array}$ & 88 \\
\hline & & $\begin{array}{l}\text { 2. SDN } 37 \\
\text { Padang Jaya }\end{array}$ & 90 \\
\hline \multirow[t]{4}{*}{11} & $\begin{array}{l}\text { Tanjung } \\
\text { Baru }\end{array}$ & $\begin{array}{l}\text { 1. SDN } 43 \\
\text { Bayua } \\
\text { Tanjung Alam }\end{array}$ & 32 \\
\hline & & $\begin{array}{lr}2 . & \text { SDN } 05 \\
\text { Sawah } & \text { Parik } \\
\text { Tanjung } & \text { Alam }\end{array}$ & 90 \\
\hline & & $\begin{array}{l}\text { 3. MIN Koto } \\
\text { Nan Tuo }\end{array}$ & 85 \\
\hline & & $\begin{array}{l}\text { 4. MIN } \\
\text { Puncak Alai }\end{array}$ & 86 \\
\hline
\end{tabular}

(Sumber: Workshop Analisis Data Kabupaten Tanah Datar, November 2008)

Data di atas menunjukkan bahwa rasio antara guru dan siswa berkisar antara 1:8. Ini berarti terjadi ketidakefisienan tenaga pendidik. Kondisi ini secara jelas akan berdampak terhadap kurangnya jam mengajar guru yang seharusnya berjumlah 24 jam perminggu (sebagai mana amanat UU Guru dan Dosen) karena alasan jumlah siswa yang sedikit. Padahal jumlah jam mengajar guru harus 24 jam tatap muka perminggu. Ini bisa diamati pada Peraturan Mentri Pendidikan Nasional No 18 Pasal 6 tahun 2007:

Guru Pegawai Negeri Sipil yang diangkat oleh Pemerintah Daerah yang telah memiliki sertifikat pendidik, nomor registrasi guru dari Departemen Pendidikan Nasional, dan melaksanakan beban guru sekurang-kurangnya 24 (dua puluh empat) jam tatap muka dalam satu minggu berhak atas tunjangan profesi pendidik sebesar satu kali gaji pokok yang dibayarkan melalui Dana Alokasi Umum terhitung mulai bulan Januari pada tahun berikutnya setelah memperoleh sertifikat pendidik.

Guru Pegawai Negeri Sipil yang diangkat oleh Pemerintah yang telah memiliki sertifikat pendidik, nomor registrasi guru dari Departemen Pendidikan Nasional, dan melaksanakan beban guru sekurang-kurangnya 24 (dua puluh empat) jam tatap muka dalam satu minggu berhak atas tunjangan profesi pendidik sebesar satu kali gaji pokok yang dibayarkan melalui Anggaran Pendapatan Belanja Negara terhitung mulai bulan Januari pada tahun berikutnya setelah memperoleh sertifikat pendidik.

Guru Non Pegawai Negeri Sipil yang diangkat oleh Badan Hukum Penyelenggara Pendidikan yang telah memiliki sertifikat pendidik, nomor registrasi guru dari Departemen Pendidikan Nasional, dan melaksanakan beban guru sekurang-kurangnya 24 (dua puluh empat) jam tatap muka dalam satu minggu berhak atas tunjangan profesi pendidik sebesar satu kali gaji pokok yang dibayarkan melalui Dana Dekosentrasi terhitung mulai bulan Januari pada tahun berikutnya setelah memperoleh sertifikat pendidik.

Dari peraturan tersebut jelas bahwa seorang guru memiliki beban tugas minimal 24 jam tatap muka dalam satu minggu. Jumlah beban ini hanya akan bisa dipenuhi dengan cara memaksimalkan tugas dan peran guru dengan baik.

Menyikapi masalah ini bisa dilakukan dengan cara membuat kelas multi grade. Pembentukan sekolah multi grade sangat penting dilakukan terutama di daerah pedesaan dimana jumlah siswa di bawah 90 orang. Mereka bisa dikelola dalam 3 rombongan belajar (rombel). Setiap rombel terdiri dari 2 kelas dan cukup 3 orang guru dan 3 ruang kelas. Hal ini sudah dilakukan di berbagai 
Negara besar, seperti Amerika Serkat, Philipina, Zimbawe, Inggris, dan Jerman. Pola ini dilakukan untuk meningkatkan efisiensi pengelolaan pendidikan dan pemanfaatan SDM. Secara teknis sekilas dapat diuraiakan contoh menghadapi kelas rangkap:

Kelas-kelas membahas tema yang sama untuk semua siswa tetapi hasil yang dharapakan dari setiap kelas mungkin berbeda. Contoh cara ini adalah anak menulis cerita/karangan/puisi dalam bahasa Indonesia tentang hal-hal yang sama tetapi hasilnya bisa berbeda susuai dengan kemampuan siswa. Hal ini bisa diterapkan dalam pelajaran lainnya seperti olah raga.

Kelas-kelas membahas materi yang berbeda. Salah satu kelas diberi kegiatan yang bersifat latihan, dan dapat dikerjakan siswa secara mandiri, sedangkan kelas kedua mengerjakan hal baru bersama guru.

Dengan cara tersebut, selain terjadi efisiensi tenaga pendidik juga diperoleh kelebihan tenaga guru. Bila pola multi grade ini diterapkan di Tanah Datar maka diperoleh kelebihan jumlah guru kelas sebanyak 41 orang, guru agama sebanyak 20 orang, dan guru olah raga sebanyak 13 orang.

Cara kedua adalah dengan meregrouping sekolah yang berdekatan. Regrouping diartikan menggabungkan dua sekolah yang memiliki jarak sangat dekat (di bawah 1000 meter). Pola ini dilakukan dengan tujuan agar diperoleh efisiensi tenaga pendidik dan tenaga kependidikan. (tenaga pendidik adalah guru, sementara tenaga kependidikan adalah kepala sekolah, tata usaha, laboran, dan tenaga kebersihan).

Jika sekolah di atas digabung akan diperoleh kelebihan tenaga pendidik sebagai berikut:

\begin{tabular}{|l|l|l|}
\hline No & Tenaga Pendidik & $\begin{array}{l}\text { Jumlah } \\
\text { Kelebihan }\end{array}$ \\
\hline 1 & Kepala Sekolah & 17 orang \\
\hline
\end{tabular}

\begin{tabular}{|l|l|l|}
\hline 2 & Guru Kelas & 11 orang \\
\hline 3 & Guru Agama & 12 orang \\
\hline 4 & Guru Olah Raga & 2 orang \\
\hline & Jumlah & 49 orang \\
\hline
\end{tabular}

Alasan regrouping tersebut antara lain:

Jarak antara satu sekolah dengan sekolah lainnya dekat $( \pm 750 \mathrm{~m})$. Mereka berada pada satu nagari yang sama.

Jumlah siswa terlihat sedikit pada dua sekolah yang berdekatan.

Jika sekolah tersebut di regrouping akan terjadi efisiensi tenaga pendidik dan kependidikan. Misalnya kepala sekolah, tenaga administrasi, guru, dan petugas kebersihan bisa disatukan.

Tentu saja sekolah yang akan diregrouping harus memperhatikan 3 hal: kondisi geografis, kondisi psikologis, dan sosiologis daerah. Apakah secara geografis kedua sekolah tersebut memungkinkan digabung. Selanjutnya, apakah jika kedua sekolah tersebut digabung tidak akan menimbulkan efek psikologis bagi guru, siswa, dan orang tua. Terakhir, apakah penggabungan dua sekolah tidak akan memiliki dampak negatif secara sosiologis. Artinya apakah kondisi masyarakat sudah siap dengan penggabungan tersebut.

Pelaksanaan regrouping, tidak bisa dipungkiri, terlihat sederhana dalam konsep tetapi tidak mudah dipraktekkan. Berbagai masalah akan berpotensi untuk muncul, baik berupa keberatan dari masyarakat (orang tua), kepala sekolah (yang akan kehilangan posisinya), maupun guru (yang harus pindah tugas).

Untuk mengantisipasi hal ini, berikut direkomendasikan beberapa hal yang bisa ditempuh sebelum betul-betul meregrouping dua sekolah:

Melakukan sosialisasi rencana regrouping kepada kedua sekolah (guru, orang tua siswa, dan masyarakat), terutama tentang alasan mengapa perlu dilakukan regrouping 


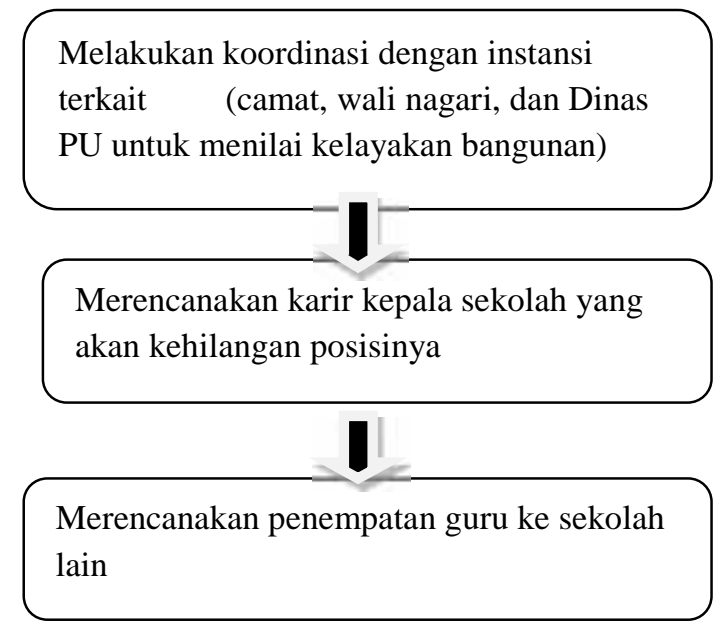

Keterangan:

Kepala cabang dinas (cabdin) melakukan sosialisasi rencana regrouping kepada ke dua sekolah (termasuk guru, orang tua dan masyarakat) diikuti alasan yang logis tentang mengapa harus diregrouping, Kepala cabdin selanjutnya melakukan koordinasi dengan diknaker, camat, dan wali nagari, dan PU untuk menilai kelayakan bangunan.

Kepala cabdin bersama Diknaker merencanakan karir kepala sekolah yang akan kehilangan posisinya, Kepala cabdin bersama Diknaker merencanakan penempatan guru ke sekolah lain.

\section{Kualifikasi Guru SD/MI dan SMP/MTs}

Berdasarkan sumber data Workshop Analisis Data Kabupaten Tanah Datar, November 2008, kualifikasi guru SD Pegawai Negeri Sipil di 14 kecamatan yang ada di Kabupaten Tanah Datar berjumlah 2518 orang dengan kulifikasi S1 567 orang, sedang S1 760 orang dan yang belum S1 1189 orang. Dengan demikian guru SD yang berkualifikasi S1 baru berjumlah 22 persen, sementara78 persen lainnya masih di bawah S1.

Jumlah Madrasah Ibtidaiyah di Kabupaten Tanah Datar sebanyak 5 MI dengan jumlah guru PNS sebanyak 39 orang, yang berkualifikasi S1 sebanyak
16 orang, sedang S1 10 orang, dan 13 orang belum S1. Dengan demikian, terdapat 41 persen guru MI yang berkualifikasi S1 dan 59 persen lainnya masih berada di bawah S1.

Guru SMP di Kabupaten Tanah Datar yang PNS berjumlah 1237 orang, yang berkualifikasi S1 berjumlah 677 orang, yang sedang S1 153 orang dan yang belum S1 sebanyak 399 orang. Jadi yang berkualifikasi S1 berjumlah 55 persen dan 45 persen lainnya belum S1.

Selanjtunnya, dari 46 MTs di Kabupaten Tanah Datar jumlah guru yang PNS sebanyak 238 orang, yang berkualifikasi S1 sebanyak 201 orang, yang sedang S1 16 orang, belum S1 sebanyak 21 orang. Jadi guru MTs di Kabupaten Tanah Datar yang berkualifikasi S1 84 persen, dan yang belum 16 persen.

Kondisi ini akan berimplikasi pada beberapa hal:

Kurang optimalnya kualitas pembelajaran di sekolah yang pada akhirnya akan berdampak negatif terhadap kualitas lulusan. Mengingat guru merupakan faktor kunci dalam proses pembelajaran, mereka harus mampu menciptakan suasana pembelajaran yang menyenangkan, kreatif, dinamis, dan dialogis.

Hilangnya kesempatan untuk mengikuti sertifikasi guru. UU No 14 tahun 2005 tentang Guru dan Dosen dalam Bab IV pasal 8 menyebutkan bahwa "guru wajib memiliki kualifikasi akademik, kompetensi, sertifikasi pendidik, sehat jasmani dan rohani, serta memiliki kemampuan untuk mewujudkan tujuan pendidikan nasional". Dan Pasal 9 disebutkan pula "Kualifikasi akademik sebagaimana dimaksud dalam pasal 8 diperoleh melalui pendidikan tinggi program sarjana atau program diploma empat".

Dari sini terlihat bahwa seorang guru wajib memiliki kualifikasi pendidikan minimal S1 atau D4. Sementara 
kenyataannya masih banyak guru yang belum berpendidikan $\mathrm{S} 1$.

Permasalahan ini sudah mendesak untuk dicarikan jalan keluarnya yaitu dengan cara membuat program peningkatan kualifikasi guru. Berikut akan dipaparkan usulan alur pelaksanaan kualifikasi guru:

\section{Pemda mengalokasikan dana APBD untuk} peningkatan kualifikasi guru

Pemda menjalin kerjasama dengan PT yang sudah terakreditasi

Pemda mengumumkan kepada masingmasing kepada sekolah tentang program peningkatan kualifikasi guru

Kepala sekolah mengusulkan guru yang diprioritaskan mengikuti program peningkatan kualifikasi guru

Pemda melaksanakan seleksi dan penetapan peserta yang akan mengikuti program peningkatan kualifikasi guru

Guru melaksanakan perkuliahan di Tanah Datar pada hari Sabtu dan Minggu

Keterangan:

Diharapkan Pemda dan Depag mengalokasikan APBD/ APBN setiap tahun untuk meningkatkan kualifikasi guru.

Selanjutnya Pemda dan Depag menjalin kerjasama dengan Perguruan Tinggi yang telah terakreditasi minimal B demi terjaminnya kualitas output lulusan.

Pemda dan Depag mengumumkan kepada masing-masing kepala sekolah tentang program peningkatan kualifikasi guru
Kepala sekolah mengusulkan guru yang diprioritaskan untuk mengikuti program peningkatan kualifikasi guru

Seterusnya Pemda dan Depag mengadakan seleksi yang ketat dan proporsional bagi guru yang akan melanjutkan pendidikan ke jenjang S1 atau D4

Untuk menghindari kekosongan proses PBM, diharapkan pola perkuliahan dilaksanakan di Tanah Datar dan waktu pelaksanaan dilakukukan pada Sabtu dan Minggu.

\section{KELEBIHAN DAN KEKURANGAN GURU SMP}

\begin{tabular}{|l|l|l|l|l|l|}
\hline No & $\begin{array}{l}\text { Mata } \\
\text { Pelajaran }\end{array}$ & Ada & Ideal & $\begin{array}{l}\text { Lebih } \\
\text { Bruto }\end{array}$ & $\begin{array}{l}\text { Lebih } \\
\text { Netto }\end{array}$ \\
\hline \hline 1 & Agama & 80 & 55 & 34 & 25 \\
\hline 2 & PPKn & 74 & 55 & 28 & 19 \\
\hline 3 & $\begin{array}{l}\text { Bahasa } \\
\text { Indonesia }\end{array}$ & 143 & 87 & 65 & 56 \\
\hline 4 & $\begin{array}{l}\text { Bahasa } \\
\text { Inggris }\end{array}$ & 93 & 87 & 24 & 6 \\
\hline 5 & $\begin{array}{l}\text { Matemati } \\
\text { ka }\end{array}$ & 117 & 87 & 44 & 30 \\
\hline 6 & IPA & 139 & 87 & 60 & 52 \\
\hline 7 & IPS & 156 & 87 & 77 & 69 \\
\hline 8 & $\begin{array}{l}\text { Seni } \\
\text { Budaya }\end{array}$ & 75 & 55 & 34 & 20 \\
\hline 9 & Penjas & 67 & 55 & 21 & 12 \\
\hline 10 & Mulok & 41 & 55 & 0 & 0 \\
\hline 11 & TIK & 7 & 55 & 0 & 0 \\
\hline 12 & BK & 33 & 55 & 0 & 0 \\
\hline & Jumlah & 1025 & 820 & 387 & 289 \\
\hline
\end{tabular}

Data di atas memperlihatkan bahwa untuk guru SMP terjadi kelebihan guru mata pelajaran sebanyak 387 orang (dalam hal ini disebut lebih bruto). Setelah dikurangi dengan beban mengajar kepala sekolah- 18 jam pelajaran dan wakil kepala sekolah- 12 jam pelajaran, diperoleh kelebihan guru sebanyak 289 orang (kelebihan netto).

Berdasarkan UU Guru dan Dosen guru wajib mengajar tatap muka 24 $\mathrm{JP} /$ minggu. Berdasarkan perhitungan jumlah guru secara global diperoleh 
kelebihan guru berjumlah 289 orang. Karena tugas kepala sekolah 6 JP maka terjadi pelimbahan tugas mengajar $18 \mathrm{JP}$ ke guru lain. JP pelimpahan terdiri $18 \mathrm{x}$ $40=720$ jam dan tugas wakil sebanyak $12 \times 80=960$ jam dan jumlah total 1680 JP setara dengan 70 guru. Dengan demikian jumlah akhir kelebihan guru secara global adalah 219 orang.

Berdasarkan data tersebut ada beberapa hal yang perlu direkomendasikan:

Secara umum terjadi kelebihan guru SMP pada beberapa bidang studi. Untuk penyebaran itu Diknaker PEMDA perlu melakukan rolling/ mutasi untuk mata pelajaran Agama, KWN, B Ind, B Ingg, Mat, IPA, IPS, Senibudaya, Penjaskes.

Diknaker PEMDA perlu mengangkat guru mata pelajaran TIK sebanyak 48 orang dan BK sebanyak 22 orang.

Untuk mengisi formasi guru Mulok dapat diberdayakan kelebihan PNS yang mempunyai kompetensi yang terkait.

Untuk memberdayakan kelebihan guru PNS dapat diberdayakan pada beberapa alternative berikut ini :

1) Mengajar pada paket B (setara SMP)

2) Ditempatkan pada SMP Swasta, MTsN atau MTs Swasta terdekat.

\section{DAFTAR PUSTAKA}

Departemen Pendidikan Nasional. Undang-Undang Guru dan Dosen.

Departemen Pendidikan Nasional. 2005. Paket Pelatihan I Pembelajaran Kelas Rangkap: Bahan Penunjang Fasilitator.

Dinas Pendidikan dan Tenaga Kerja Tanah Datar. 2008. Workshop Pemetaan Sekolah dan Madrasah Kabupaten Tanah Datar.

Direktorat Jendral Peningkatan Mutu dan Tenaga Kependidikan. 2007.
3) Bagi guru yang tidak efektif mengajar ditawarkan untuk pensiun muda atau alih fungsi

\section{KESIMPULAN}

Berdasarkan uraian yang telah dikemukakan sebelumnya dapat dinyatakan beberapa kesimpulan:

Pengelolaan pendidikan membutuhkan efisiensi dan efektifitas tenaga pendidik dan tenaga kependidikan.

Sekolah Dasar yang memiliki jumlah siswa di bawah 90 orang diharapakan membuat kelas multi grade dalam rangka efisiensi tenaga pengajar. Namun pembuatan kelas multi grade membutuhkan kajian yang lebijh intens dan membutuhkan guru yang qualified.

Apabila ada dua Sekolah dasar yang memilki jarak di bawah 1000 meter bisa dilakukan penggabungan (regrouping) agar terjadi efisiensi tenaga pendidik dan tenaga kependidikan.

Sekolah yang memiliki kelebihan guru diharapkan mendistribusikan ke sekolah yang memiliki kekurangan guru lain melalui kebijakan Dinas Pendidikan Tenaga Kerja.

Peningkatan kualifikasi tenaga pendidik mendesak untuk diselesaikan mengingat amanat UU Nomor 14 tahun 2004.

Panduan Peningkatan Kualifikasi Pendidikan kepala Sekolah dan Pengawas. Jakarta

Managing Basic Education Project. 2008. Kerjasama pemerintah Indonesia dan Australia. Pelatihan Analisis Data Pemetaan Sekolah.

Nanang Rijono. 2008. Kualifikasi Guru dihadang masalah Klasik: Dana, Ya dana, Dana...!

S.F. Research Center. Kualifikasi Guru. 

* Penulis adalah Lektor dalam Mata Kuliah Bahasa Inggris pada STAIN Batusangkar 